\title{
Pensar Contra os Dualismos: resenha de filosofia ciborgue
}

\author{
Adriano Carvalho Araujo e Sousa' \\ http://orcid.org/0000-0002-9180-2409 \\ I - UFSC \\ São Carlos (SP). Brasil
}

\section{HOQUET, T. Filosofia ciborgue:}

pensar contra os dualismos.

Trad. Marcio Honorio de Godoy.

São Paulo: Perspectiva, 2019, 376 p.

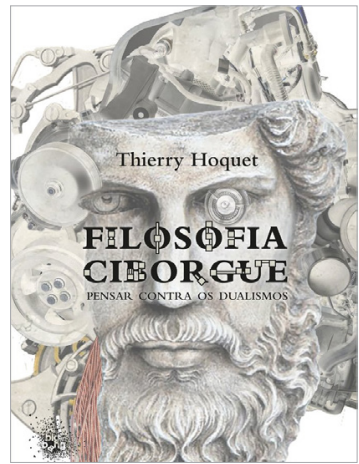

Resumo: Na experiência contemporânea, a multiplicação de próteses, interfaces e máquinas convoca imediatamente a pensar ciborgue como o que problematiza relações entre natureza e artifício. Ciborgue comporta diversidade, pode se constituir a partir de uma intervenção cirúrgica ou como um Organorg. Thierry Hoquet observa exemplos no cotidiano e nas artes, propõe cartografar o lugar ocupado por esse corpo tecnológico no pós-humano e por um novo feminismo pensado a partir dessas categorias.

Palavras-chave: ciborgue; Organorg; pós-humano; feminismo.

Abstract: Thinking against dualisms: review of cyborg philosophy - In the condition of contemporary experience, the multiplicity of protheses, interfaces and machines immediately calls to think about the idea of cyborg as the concept which problematizes the relationships between nature and artifact. Cyborg bears diversity: it consists in a surgical intervention or an Organorg. Thierry Hoquet, the french philosopher, observes everyday artistic examples, proposes mapping of the place occupied by this technological body and by a new feminism, thought through these categories, in the posthuman.

Keywords: cyborg; Organorg; posthuman; feminism.

Em Filosofia Ciborgue, Thierry Hoquet oferece ao leitor contribuição a um debate contemporâneo e propõe questionamentos sempre instigantes, de um ponto de vista epistemológico. O conjunto de ensaios aí reunidos aborda transformações em nosso 
entendimento de humano numa sociedade cada vez mais envolvida com ciborgues, que embaralham as distinções entre natureza e artifício, entre humano e máquina.

$\mathrm{O}$ autor estabelece suas bases no pensamento de Donna Haraway, que publicou um Manifesto Ciborgue em 1985, cujo objetivo era desenvolver questões a partir do corpo e do feminismo, que ela pretendia debater sem voltar-se para a questão do renascimento. Em vez disso, a professora norte-americana apontava a premência de temas como a regeneração: "Temos urgência de regeneração, não de renascimento, e as possibilidades de nossa reconstituição incluem o seguinte sonho utópico - a esperança de um mundo monstruoso sem gênero" (HARAWAY, 1991, p. 181).

Por sua vez, Hoquet segue linha de raciocínio que procura compreender Ciborgue, grafado em caixa-alta mesmo, como personagem que escapa aos dualismos herdados da filosofia cartesiana. Localiza a questão entendendo Ciborgue como necessariamente torto, mas que permitirá pensar um novo feminismo caso este pretenda evitar as lógicas da dominação orgânica, ou seja, a mesma colocada sempre em termos de um dualismo. Para o autor, a questão é afirmar outros possíveis: "por exemplo, de híbridos de máquina e organismo ou de animal e humano" (HOQUET, 2019, p. 108).

Ciborgue seria portanto o que se opõe à forma mais tradicional que o autor nomeia com a terminologia anglo-saxã de "french-feminism", responsável por demarcar uma identidade. Em outras palavras, Ciborgue materializa um feminismo da diferença ou universalista, proporcionando uma multiplicidade, inclusive terminológica: comparecem aí Stuffs, Organorgs etc. Não se trata de uma oposição a movimentos sociais, longe disso (o livro é dedicado ao feminismo!), mas sim de pensar um de seus legados e a lição que nos deixa: "todas as dicotomias repetem e declinam o sintagma 'diferença de sexos', essa diferença, ela mesma, não passando de um quadro rígido sobreposto à pluralidade anárquica das genitálias." (ibidem, p. 293)

Na concepção de Hoquet, em vez de defender uma identidade, a personagem de Ciborgue quer outros possíveis. Pretende ser a conjunção entre masculino e feminino que não é nem um nem outro, volta-se contra uma ideia de gênero tradicional e, principalmente, funda um novo em que a técnica pode desempenhar papel libertador. Por isso, o autor rejeita o artigo (sem o ou a ciborgue, sem o humano) e propõe utilizar o pronome-neologismo "Ille", que a tradução verteu acertadamente como "elela". Estranhamento linguístico cujo uso de iniciais maiúsculas para outros nomes, justifica por se tratarem de personagens filosóficas.

Tal artifício do autor conduz a leitura constantemente a problematizações: "Elela é a pós-modernidade ou a modernidade elevada à categoria de mitologia? Talvez tudo isso ao mesmo tempo. É por isso que o paradoxo, como um meio de manter todas essas facetas juntas, será, quem sabe, a forma lógica mais apropriada para se pensar Ciborgue". (ibidem, p. 192)

Hoquet vai buscar apoio nos exemplos mais variados. Na mídia e nas ruas, encontra a figura do homem-pássaro suíço, cuja máquina lhe proporciona alcançar velocidades extremas; e um eyeborg, um inglês que utiliza uma prótese para visualizar as cores com seus ouvidos. O ensaísta francês oferece-nos ainda comentários que vão desde 
a animação com Ghost in The Shell, até o cinema com RoboCop e O Exterminador do Futuro. Respectivamente, observa a Major Kusanagi, o corpo dilacerado do policial Murphy, transformado em cibernético no filme de Verhoeven, mas também comenta o walkman de Ginger no longa-metragem com Schwarzenegger, levando a pensar no que se metamorfosearam os organismos ou melhor, Organorgs. O walkman de Ginger é expressão perfeita da mistura entre organismo e máquina em sua forma mais harmoniosa, completamente acoplados, interfaceados, sem enxertos, nem cirurgia.

Daí a série de acoplamentos que se dão com os trajes para nadadores ou mesmo com o cidadão comum, ele próprio Ciborgue que, cada um a sua maneira, vai propiciar "criaturas nas quais natureza e artifício são indissociáveis" (ibidem, p. 281), seja através da incisão cirúrgica, seja através de simbioses com máquinas, interfaces, próteses etc. O pós-humano por excelência: "É então a angústia, e não mais a esperança, que acompanha a perspectiva do nascimento. Pois o nascimento de ciborgue é o de um monstro, do alienado, do escravo, dos íncubos e súcubos, dos bebês de Rosemary. Ciborgue substitui, prolonga, sublima, abole humano, suscitando entre aquelelas que assistem ao seu nascimento um legítimo temor e uma compreensível comoção." (ibidem, p. 204)

Em sentido artístico, a performance também comparece no ensaio. Hoquet menciona artistas do porte de Orlan, Stelarc e Eduardo Kac. A dança surge entre outros momentos nas infinitas reconfigurações de Ciborgue em sua "coreografia ontológica" (HARAWAY, 2003, p. 11 e 51).

Assim, pode-se dizer que a chegada em português deste Filosofia ciborgue disponibiliza materiais que interessam imediatamente aos campos da comunicação, filosofia e artes que permitirão um seguimento contemporâneo a reflexões sobre corpo, feminismo e técnica, todos temas com a urgência de resistir sob a forma do que não tem forma: a monstruosidade, o ciborgue.

Adriano Carvalho Araujo e Sousa é pós-doutorando no pós doutorando em Estudos Literários na UFSCAR. É doutor em Comunicação e Semiótica pela Pontifícia Universidade Católica de São Paulo (2010), sob a orientação de. Jerusa Pires Ferreira. Desenvolveu parte de sua pesquisa em estágio PDEE / CAPES junto ao Centre de Recherche sur I'Intermédialité da Universidade de Montreal sob a supervisão de Silvestra Mariniello. É autor de Poética de Júlio Bressane: Cinema(s) da Transcriação (Fapesp/Educ, 2015). Suas pesquisas tratam do cinema de Júlio Bressane e da ideia de transcriação, concebida pelo poeta, tradutor e crítico literário Haroldo de Campos. Seus resultados conduzem a uma reflexão sobre as relações entre cinema e outras artes tanto quanto à ideia de tradução cultural.

logodedalo@hotmail.com 


\section{Referências}

HARAWAY, D. [1985] A Cyborg Manifesto: Science, Technology, and Socialist-Feminism in the Late Twentieth Century. In: Haraway, D. Simians, Cyborgs, and Women: The Reinvention of Nature. New York: Routledge, 1991, p.149-181.

Companion Species Manifesto: dogs, people, and significant Otherness. New York: Prickly Paradigm Press, 2003.

HOQUET, T. Filosofia ciborgue: pensar contra os dualismos. Tradução de Marcio Honorio de Godoy. São Paulo: Perspectiva, 2019.

PAVIS, P. Ciborgue. In: PAVIS, P. Dicionário da Performance e do Teatro Contemporâneo. São Paulo: Perspectiva, 2017.

Texto recebido em 10/07/2019

e aprovado em 21/07/2019. 